\title{
Unprotected left main coronary artery stenting with everolimus (Xience V) drug-eluting stents: A single center retrospective experience
}

\author{
Juan C. Fernandez-Guerrero*, Juan A. Herrador, Manuel Guzman, Victor Aragon, Carmen Adamuz \\ Unidad de Hemodinámica, Servicio de Cardiología, Complejo Hospitalario de Jaén, Jaén, Spain \\ Email: ${ }^{*}$ jcfgfernandez@yahoo.es
}

Received 12 January 2013; revised 28 February 2013; accepted 5 April 2013

Copyright (C) 2013 Juan C. Fernandez-Guerrero et al. This is an open access article distributed under the Creative Commons Attribution License, which permits unrestricted use, distribution, and reproduction in any medium, provided the original work is properly cited.

\begin{abstract}
Objectives: We sought to evaluate the efficacy and safety of unrestricted implantation of everolimus eluting stent Xience V (EES-XV) in a cohort of realworld patients with unprotected left main coronary disease (ULMCD). Background: The second-generation EES-XV stent is currently one of the most commonly used drug-eluting stents in clinical practice. It has been shown to be superior to paclitaxel-eluting stents, but its relative merits on unprotected left main coronary disease have been less extensively assessed. Methods: Between 2007 and 2010, in this single-center registry, we evaluated the clinical outcomes of 98 patients with ULMCD who underwent percutaneous coronary intervention (PCI) with EES-XV. Results: There were no in-hospital deaths. At $25.63 \pm 14.41$ months of follow-up, 17 patients (17.3\%) experienced major adverse coronary event (MACE), death from cardiovascular disease $(n=6 ; 6.1 \%)$ and target lesion revascularization (TLR; $n=7 ; 7.1 \%$ ). The predictors of death from cardiovascular disease were: previous PCI and left ventricular dysfunction. The only predictor of TLR was the placement of $\mathbf{2}$ stents in the left main coronary artery. Conclusions: In this singlecenter real-world registry, we found that elective ULMCD stenting with EES-XV provided good short-, medium- and long-term outcomes, with an estimated cumulative need for TLR of $\mathbf{7 . 1 \%}$, a cardiac mortality rate of $6.1 \%$, and a MACE rate of $17.3 \%$ at 2 years.
\end{abstract}

Keywords: Percutaneous Coronary Interventions; "Off Label" Lesions; Prognosis

\footnotetext{
"Corresponding author.
}

\section{INTRODUCTION}

Traditionally, coronary artery bypass graft (CABG) has been considered the gold standard treatment for obstructtive disease of the LMCA [1]. However, recent studies have demonstrated an acceptable safety profile for percutaneous coronary interventions (PCI) with stenting for unprotected left main coronary artery (ULMCA) lesions. The PCI procedure is becoming more commonly used despite the available data [2-7] being limited to first generation drug-eluting stents (DES) such as sirolimuseluting stents (SES) and paclitaxel eluting stents (PES). The XIENCE V everolimus eluting stent (EES-XV) was designed to release everolimus from a thin $(7.8 \mathrm{~mm})$, non-adhesive, durable, biocompatible, fluorinated, copolymer coated onto a low profile, flexible, cobalt-chromium, stent with $0.003200 \mathrm{~mm}$ strut thickness. A number of randomized controlled trials have demonstrated its superiority over the first-generation PES [8-11].

Recently, a meta-analysis of randomized clinical trials comparing outcomes of EES-XV vs. SES did not show any statistically significant differences between the stents [12]. Although there are data from off-label studies on the safety and efficacy of EES-XV stent use, to date there have not been any publications that have specifically evaluated the medium-to-long-term use of EES-XV in ULMCA lesions [13].

The aim of the present, single-centered, "real-world" registry was to examine prospectively the medium-to-longterm outcome of patients who underwent elective PCI for ULMCA disease using only 1 type of DES; the EES-XV.

\section{METHODS}

\subsection{Patients}

We retrospectively assessed patients with ULMCA le- 
sions treated with EES-XV between March 2007 and July 2010 in our Cardiology Unit of the Complejo Hospitalario de Jaén (Spain). Presence of other types of ULMCA stents, shock at presentation or previous coronary artery bypass graft (CABG) with at least one permeable bridge in the left coronary artery (protected left main) were considered as the exclusion criterion. All procedures were approved by the Institution Review Board (IRB) of the Hospital and all patients provided written consent to participation in the study. Data for inclusion into the registry were coded so as to maintain anonymity. During the period of the study, 180 patients were diagnosed with stenosis involving the LMCA; 33 patients were referred for revascularization surgery, 10 patients were excluded because of cardiogenic shock at the time of the angiography, 4 patients had CABG (protected LM) and 35 patients had a different stent to that of the EES-XV implanted in the LMCA. In these patients there had not been an EES-XV implant in the LMCA in the majority of the cases due to stent measurement $\geq 4.5$ $\mathrm{mm}$ diameter. The remaining 98 patients are the subject of the present study.

Indications for angiography ranged from acute coronary syndrome (ACS), defined as those patients being evaluated for ST-segment elevated myocardial infarction (STEMI), non-ST-segment elevated MI (NSTEMI), or unstable angina (UA), and those with stable angina with or without high risk ischemia.

\subsection{Procedure}

Cases were collected from several operators using the femoral artery approach. Interventional techniques and medications were at the discretion of the individual attending cardiologists but under current clinical guidelines including the use of intra-aortic balloon pumps (IABPs), intra-vascular ultrasound (IVUS) and glycolprotein IIb/IIIa inhibitors.

ULMCA lesions were defined as: ostial, midshaft or distal/bifurcation. The presence of multi-vessel disease vs. the isolated ULM disease was also recorded.

Angiographic success was defined as stenosis $<30 \%$ and thrombolysis in myocardial infarction (TIMI) 3 flow in the stented lesion, and $<50 \%$ in the unstented SB. Procedural success was defined as the absence of procedural complications, or major adverse cardiac events (MACE) within the setting of angiographic success.

Cardiac enzymes serial measurements and electrocardiograms (ECGs) were performed post-procedure.

Following the index intervention, patients were maintained on dual anti-platelet therapy with acetylsalicylic acid (ASA; $100 \mathrm{mg}$ daily) indefinitely and clopidogrel $(75 \mathrm{mg} / \mathrm{d})$ for a minimum of 12 months.

\subsection{Study Definitions}

The primary endpoint was MACE, as defined by death, non-fatal acute myocardial infarction (AMI), and target lesion revascularization (TLR) over the period of follow-up.

Death was classified as cardiac or non-cardiac. Deaths due to undetermined causes were classified as cardiac. A diagnosis of AMI was based on total creatine kinase (CK) elevated by $>3$ times the upper limit of normal (ULN) with a concomitant elevation of troponin I. TLR was defined as any repeat percutaneous intervention or surgical bypass of the target lesion performed for $>50 \%$ restenosis of the treated segment from $5 \mathrm{~mm}$ proximal to the stent and $5 \mathrm{~mm}$ distal to the stent in the LMCA.

Restenosis was defined as $>50 \%$ angiographic narrowing of any previously successfully treated lesion.

Stent thrombosis (ST) was defined, according to the Academic Research Consortium, as definite, probable, or possible [14].

Target vessel revascularization (TVR) was defined as any new revascularizations of the patient in follow-up due to a restenosis or progressive disease in the rest of the coronary arteries (excluding the LMCA).

The European System for Cardiac Operative Risk Evaluation (EuroSCORE) was used to stratify the risk of death at 30 days. Patients were stratified as "high risk" in the presence of a logistic EuroSCORE of 6.

For the present study, the Syntax Score (SS) for each angiogram was assessed by one experienced intervenetional cardiologist. Each lesion with $>50 \%$ diameter stenosis in vessels $>1.5 \mathrm{~mm}$ in diameter was scored using the SS algorithm, fully described elsewhere [15].

\subsection{Patient Follow-Up Procedures}

All patients were followed-up by outpatient clinical visit or telephone call at 1 month, 6 months, 1 year, and currently up to Aug. 2011. When the patient was lost to follow-up, the family, physician, or cardiologist was contacted. In case of failure to contact any of the persons responsible, information regarding death was obtained from the population registry. Follow-up angiography was performed only in case of clinical indications, as judged by the attending physician; essentially following signs or symptoms suggestive of angina or ischemia.

\subsection{Statistical Analyses}

Continuous variables are presented as mean \pm standard deviation (SD) and the categorical variables as percentage frequencies. The continuous variables were compared using the Student t-test. Categorical variables were compared with the chi-square or the Fisher exact test. Univariate and multivariate logistic regression analyses 
were used to identify independent predictors of MACE. For each of the events-of-interest considered, observation time began on the date of stent implantation and ended either on the date of MACE occurrence or on the last day of patient contact, whichever occurred first. Cox proportional hazard models were fitted for comparisons of selected outcomes of patient or procedural characteristics. All analyses were performed using the SPSS software package (version 15.0). A value of $\mathrm{p}<0.05$ was considered statistically significant.

\section{RESULTS}

\subsection{Baseline Clinical Data}

Baseline clinical characteristics are presented in Table $\mathbf{1 .}$ Included in the study were 98 patients undergoing elective PCI for ULMCA disease using the EES-XV at our Center during the study period. Patients in this cohort had cardiovascular disease risk factors such as diabetes mellitus (40.8\% of cases), hypertension (65.3\%), hypercholesterolemia (54.1\%), and smoking habit (46.9\%); $71.4 \%$ underwent PCI for NSTEACS and $40.8 \%$ presented high-risk (additive EuroSCORE $>6$ ).

Table 1. Baseline demographic and clinical characteristics of the 98 patients entered in the registry.

\begin{tabular}{|c|c|c|}
\hline \multicolumn{2}{|c|}{ Characteristic } & \multirow{2}{*}{$\frac{\mathrm{N}}{66.53 \pm 10.06}$} \\
\hline Age; mean \pm SD & & \\
\hline Males; n (\%) & & $75(76.5)$ \\
\hline \multicolumn{3}{|l|}{ Risk factors; n (\%) } \\
\hline & Diabetes & $40(40.8)$ \\
\hline & Hypertension & $64(65.3)$ \\
\hline & Hypercholesterolemia & $53(54.1)$ \\
\hline & Smoking habit & $46(46.9)$ \\
\hline Previous AMI; n (\%) & & $23(23.5)$ \\
\hline Previous PCI; n (\%) & & $20(20.4)$ \\
\hline \multicolumn{3}{|l|}{$\begin{array}{l}\text { Clinical indication } \\
\text { for intervention; } \mathrm{n}(\%)\end{array}$} \\
\hline & Stable angina & $22(22.4)$ \\
\hline & UA/NSTEMI & $70(71.4)$ \\
\hline & Post-STEMI & $6(6.1)$ \\
\hline $\mathrm{LVEF} ; \%$ mean $\pm \mathrm{SD}$ & & $62.56 \pm 13.09$ \\
\hline \multicolumn{3}{|l|}{ Syntax score (SS) } \\
\hline & mean $\pm \mathrm{SD}$ & $25.61 \pm 10.19$ \\
\hline & $\mathrm{SS}>32, \mathrm{n}(\%)$ & $23(23.5)$ \\
\hline $\begin{array}{c}\text { High-risk (additive } \\
\text { EuroSCORE > 6); n (\%) }\end{array}$ & & $40(40.8)$ \\
\hline
\end{tabular}

\subsection{Angiographic and Procedural Data}

The angiographic and procedural data are presented in Table 2. There were 77 patients $(78.6 \%)$ who had distal LMCA bifurcation disease. In most patients $(72.5 \%)$ a provisional T-stenting technique had been used. There were 9 patients $(9.2 \%)$ treated with 2 stents technique: 8 patients crush/minicrush technique and 1 patient "V" stenting technique. The mean Syntax Score (SS) was $25.61 \pm 10.19$. There were 52 patients $(53 \%)$ who had multi-vessel disease. The mean length of stent used was $72.35 \pm 44.61 \mathrm{~mm}$. Quantitative angiographic data of treated lesions are presented in Table 3 .

Table 2. Baseline lesion and procedural characteristics in the 98 patients.

\begin{tabular}{|c|c|c|}
\hline \multicolumn{2}{|c|}{ Characteristic } & $\mathrm{N}$ \\
\hline \multicolumn{3}{|l|}{$\begin{array}{l}\text { Vessels treated per } \\
\text { patient; } \mathrm{n}(\%)\end{array}$} \\
\hline & LM only & $16(16.3)$ \\
\hline & $\mathrm{LM}+1$ vessel & $30(30.6)$ \\
\hline & $\mathrm{LM}+2$ vessels & $36(36.7)$ \\
\hline & $\mathrm{LM}+3$ vessels & $16(16.3)$ \\
\hline $\begin{array}{l}\text { Overall stent length; } \\
\text { mm, mean } \pm \mathrm{SD}\end{array}$ & & $72.35 \pm 44.61$ \\
\hline \multirow[t]{8}{*}{$\begin{array}{l}\text { Distal LM artery } \\
\text { bifurcation; } \mathrm{n}(\%)^{*}\end{array}$} & & $77(78.6)$ \\
\hline & Type $1-0-0$ & $6(6.1)$ \\
\hline & Type 1-1-0 & $24(24.5)$ \\
\hline & Type 1-1-1 & $21(21.4)$ \\
\hline & Type $0-1-0$ & $14(14.3)$ \\
\hline & Type 0-0-1 & $2(2.0)$ \\
\hline & Type $0-1-1$ & $6(6,1)$ \\
\hline & Type 1-0-1 & $4(4.1)$ \\
\hline \multicolumn{3}{|l|}{$\begin{array}{l}\text { Bifurcation treatment } \\
\text { technique; } \mathrm{n}(\%)\end{array}$} \\
\hline & Provisional T (1 stent) & $66(67.4)$ \\
\hline & Provisional T (2 stents) & $5(5.1)$ \\
\hline & Crush/minicrush & $8(8.2)$ \\
\hline & "V" stenting & $1(1)$ \\
\hline Final kissing balloon, n (\%) & & $50(51)$ \\
\hline $\begin{array}{c}\text { Intravascular ultrasound } \\
\text { used, } \mathrm{n}(\%)\end{array}$ & & $65(66.3)$ \\
\hline $\begin{array}{l}\text { Intra-aortic balloon } \\
\text { pump; n }(\%)\end{array}$ & & $2(2)$ \\
\hline $\begin{array}{l}\text { Glycoprotein IIb/IIIa } \\
\text { inhibitor; } \mathrm{n}(\%)\end{array}$ & & $41(41.8)$ \\
\hline
\end{tabular}

${ }^{*}$ The coronary bifurcation lesion classification proposed by Medina; LM = left main. 
Table 3. Quantitative angiographic analysis of treated lesions $(\mathrm{n}=98)$.

\begin{tabular}{lcc}
\hline \multicolumn{1}{c}{ Variable } & Before procedure & After procedure \\
\hline $\begin{array}{l}\text { LM reference diameter, } \\
\mathrm{mm} \pm \mathrm{SD}\end{array}$ & $3.42 \pm 0.52$ & $3.74 \pm 0.53$ \\
$\begin{array}{l}\mathrm{LM} \text { minimum lumen diameter, } \\
\mathrm{mm} \pm \mathrm{SD}\end{array}$ & $1.12 \pm 0.42$ & $3.19 \pm 0.52$ \\
$\begin{array}{l}\mathrm{LM} \text { percent stenosis, } \% \pm \mathrm{SD} \\
\mathrm{SB} \text { reference diameter, }\end{array}$ & $68 \pm 12.17$ & $14.09 \pm 6.09$ \\
$\mathrm{~mm} \pm \mathrm{SD}$ & $2.84 \pm 0.86$ & $3.01 \pm 0.74$ \\
$\begin{array}{l}\mathrm{SB} \text { minimum lumen diameter, } \\
\mathrm{mm} \pm \mathrm{SD}\end{array}$ & $1.30 \pm 1.06$ & $2.34 \pm 0.77$ \\
$\begin{array}{l}\mathrm{SB} \text { percent stenosis, } \% \pm \mathrm{SD} \\
\text { Angiographic success, }\end{array}$ & $42.79 \pm 36.79$ & $24.74 \pm 22.63$ \\
$\%$ of patients & & 100 \\
\hline
\end{tabular}

$\mathrm{LM}=$ left main; $\mathrm{SB}=$ side branch.

\subsection{In-Hospital Outcomes}

Angiographic success was achieved in $100 \%$ of patients. There were no deaths nor need for emergency revascularization during hospitalization. There were 15 patients (15.3\%) who had elevated levels of markers of myocardial damage after PCI, of whom only 3 had a significant elevation of $\mathrm{tnI}(>20 \mathrm{ng} / \mathrm{dL})$. These patients had multivessel disease which required multi-stenting.

\subsection{Long-Term Outcomes}

At $25.63 \pm 14.41$ months of follow-up (range: 1 - 53 months), 17 patients (17.3\%) experienced MACE. Data are summarized in Table 4. Twelve patients died during follow-up; 6 from non-cardiac causes (4 from cancer, 1 pulmonary thromboembolism and 1 cerebrovascular accident); 6 patients died from cardiovascular causes (see Table 5). There were 7 patients $(7.1 \%)$ who underwent revascularization of the LMCA due to clinical recurrence and angiographic restenosis of the stent: 2 restenoses of the ostia of the TCI (proximal border of the stent), one focal restenosis of the circumflex artery origin, one focal restenosis of the body of the stent, and 3 diffuse restenoses of the stents. Five patients were treated with a repeat $\mathrm{PCI}$ and 2 cases were referred for CABG.

\subsection{Predictors of MACE}

The following variables were entered into a stepwise multivariable Cox proportional hazard model for longterm survival and event-free survival: age, gender, left ventricular ejection fraction (LVEF), ventricular dysfunction ( $\mathrm{EF}<40 \%$ ), prior MI, prior PCI, hypertension, hypercholesterolemia, diabetes, smoking, use of glycolprotein IIb/IIIa antagonists, Euro-SCORE (Euro-SCORE $\geq 6$ ), SYNTAX score (SYNTAX score $\geq 33$ ), distal bifurcation lesion, 2 implants in the LMCA, dimensions of the
Table 4. Long-term outcomes.

\begin{tabular}{cc}
\hline Outcome & Number of patients (\%) \\
\hline MACE & $17(17.3)$ \\
Total mortality & $12(12.2)$ \\
Cardiac death & $6(6.1)$ \\
Myocardial infarction & $4(4.1)$ \\
Target lesion revascularization & $7(7.1)$ \\
Target vessel revascularization & $10(10.2)$ \\
\hline
\end{tabular}

stents implanted, IVUS, kissing balloon technique. The predictors of cardiovascular death in follow-up were: previous revascularization and left ventricular dysfunction. The only predictor of AMI in follow-up was having had a previous PCI (in any vessel) and the predictor of TLR was the implantation of 2 stents in LMCA (Table 6).

\section{DISCUSSION}

The major findings of this single-center, observational study are: 1) PCI with EES-XV in ULMCA is feasible and has high clinical and procedural success rates; 2) A low rate of MACE during follow-up $(25.63 \pm 14.41$ months); 3) The independent predictors of cardiovascular death were previous PCI and left ventricular dysfunction.

Literature data on long-term outcomes post-PCI in the LMCA population are scarce. Park et al. [16] reported 3-year safety composite rates (death, Q-wave MI, or stroke) of $9.7 \%$, with TVR rate of $12.6 \%$. Vaquerizo et al. [17] demonstrated, in 291 patients from a multi-centered registry, the device-oriented composite end point at 2 years of $12.6 \%$ post-UCLMA stenting with paclitaxeleluting stents. In the DELFT (Drug-Eluting Stent for Left Main) registry, Meliga et al. [18] reported 3-year MACE rate (a composite of cardiac mortality, MI, and TVR) of $26.5 \%$, cardiac mortality of $9.2 \%$, and TLR of $14.2 \%$. Wood et al. [19], in a long-term follow-up of 100 patients with high surgical risk post-PCI, observed allcause mortality at 28 months of $21 \%$, with event-free survival around $65 \%$ at 27 months

Toyofuku et al. [20] published their 3-year follow-up of 582 patients treated with Cypher stent implant (SES) en ULMCA patients in the j-Cypher registry. In a patient population with similar characteristics to our study, the event rates observed were very similar to ours $(14.6 \%$ all-cause deaths, $7.3 \%$ cardiac deaths, $3.7 \%$ myocardial infarction, $14.8 \%$ TLR).

In a single-centered registry of patients with lesions treated with PCI with SES, XiaFan Wu et al. [21] reported an incidence of cardiac death of $4 \%$ and TLR of $11.9 \%$ at 3 years of follow-up. Impaired LVEF $(<40 \%)$ 
Table 5. Characteristics of the patients in whom the outcome was cardiac death in the course of follow-up.

\begin{tabular}{|c|c|c|c|c|c|c|c|c|}
\hline Patient & Age & Gender & $\mathrm{EF}$ & Type of lesion & Technique & IVUS & Months post-PCI & Comments \\
\hline 1 & 72 & $\mathrm{~F}$ & 70 & Distal & "V" stenting & No & 37 & Sudden death \\
\hline 2 & 75 & M & 55 & Distal & "Crush" stenting & Yes & 11 & Restenosis of both ostia, death during re-PCI \\
\hline 3 & 74 & M & 55 & Distal & PTS (1 stent) & Yes & 4 & $\begin{array}{l}\text { Restenosis with thrombus } \rightarrow \text { CABG } \rightarrow \\
\text { death post-operative }\end{array}$ \\
\hline 4 & 71 & M & 60 & Midshaft & Direct stenting & Yes & 19 & $\begin{array}{l}\text { Restenosis of a stent inserted in the anterior } \\
\text { descending artery } \rightarrow \text { cardiogenic shock }\end{array}$ \\
\hline 5 & 77 & M & 19 & Distal & PTS (1 stent) & No & 3 & Cardiac death \\
\hline 6 & 61 & $\mathrm{~F}$ & 34 & Distal & PTS (1 stent) & Yes & 8 & Sudden death \\
\hline
\end{tabular}

Gender $(\mathrm{M}=$ male, $\mathrm{F}=$ female $)$, EF = ejection fraction; IVUS = intra-vascular ultra-sound; PTS = provisional "T" stenting; CABG = coronary artery bypass graft.

Table 6. Multivariate analyses.

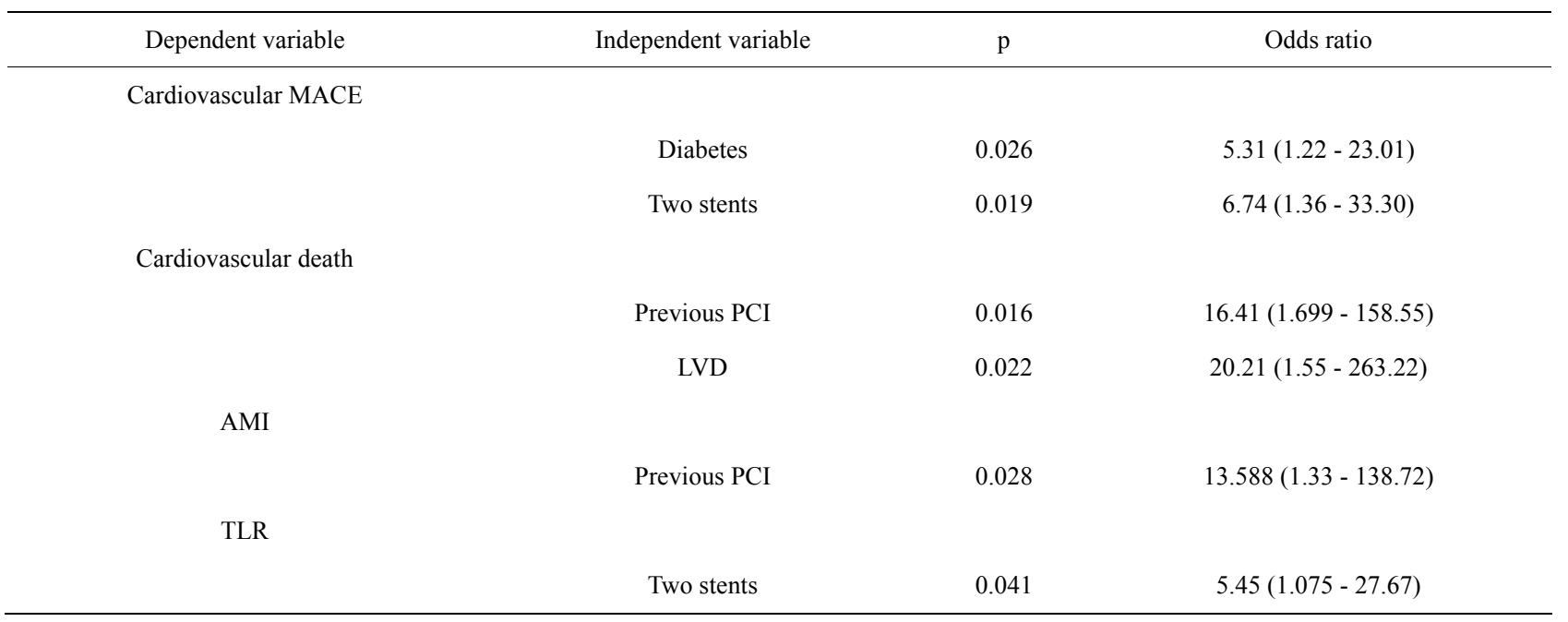

PCI = percutaneous coronary intervention; $L V D=$ left ventricular dysfunction; TLR: target lesion revascularization.

and high surgical risk (Euroscore $>6$ ) were the independent predictors of MACE.

Data from ISAR-LEFT-MAIN (Intracoronary Stenting and Angiographics Results: Drug-Eluting Sents for Unprotected Coronary Left Main Lesions) trial [4] and sub-analysis of the MAIN-COMPARE (Revascularization for Unprotected Left Main Coronary Artery Stenosis: Comparison of Percutaneus Coronary Angioplasty Versus Surgical Revascularization) registry [22] showed that SES and PES were equally effective and safe in patients undergoing ULMCA stenting.

To date, there have not been any studies published that evaluated the use of EES-XV in patients with ULMCA. Our study results demonstrated that treatment with EES$\mathrm{XV}$ offers excellent medium-term results, comparable with respect to efficacy and safety to the published findings in $1^{\text {st }}$ generation pharmaco-active stents. Despite excluding cardiogenic shock, this cohort of patients can be considered at high risk of ischemic events in follow-up. The patients are, in greater part, those with distal LMCA lesions (78.6\%), high percentage with diabetes
(40.8\%), with multiple lesions apart from LMCA (72.35 $\pm 44.61 \mathrm{~mm}$ total stent length) and $40.8 \%$ with high-risk (additive EuroSCORE > 6). Taking into account these characteristics we believe that the use of the EES-XV in ULMCA patients results in a low rate of MACE, at least in the medium term.

Latib et al. [23] demonstrated that the use of EES-XV in off-label lesions offered excellent results. Real-world registry of patients of high angiographic complexity entered in clinical trials show a cumulative MACE of $10.6 \%$ and TLR of $7.9 \%$.

In our study the only predictors of cardiovascular death were left ventricular dysfunction (LVD) and previous percutaneous revascularization. LVD is a known predictor of cardiovascular mortality. Previous percutaneous revascularization can highlight a group of patients with long-term coronary disease, or even identify a group of patients in whom PCI with stent implant would not be a good option. In this sub-group of patients, perhaps surgical revascularization of the coronaries could be the preferred therapeutic option. 
Another aspect of note in our study is that the only predictor of TLR in follow-up is the insertion of 2 stents in the LMCA lesions involving bifurcation. This finding can have two interpretations: 1) A strategy of 2 stents in bifurcation lesions of ULMCA carries a higher rate of TLR in follow-up; 2) Two stents are used only for bifurcation lesions of high angiographic complexity (very calcified lesions, very severe lesion of both ostia) which carry high risk of restenosis and TLR in follow-up. The only way to clarify this question would be to conduct a randomized clinical trial with 2 strategies (1 or 2 stents) in true bifurcation lesions $(\mathrm{X}, 1,1)$ of ULMCA.

EES has been proposed as having a theoretical advantage over first-generation DES in relation to safety i.e. the thin strut design might result in more rapid stent endothelialization $[24,25]$. Our study was unable to demonstrate this contention, but there was a low incidence of thrombosis in whatever presentation (definite, probable, possible).

\subsection{Limitations}

The present study was non-randomized, with a relatively small sample size, and a relatively short follow-up. Comparison with surgical revascularization was not performed for this patient sub-group. Follow-up angiography was not performed in all patients. Hence, the true restenosis rate cannot be known.

\subsection{Conclusion}

In this single-center real-world registry, we found that elective ULMCA stenting with EES-XV, provided good short-, medium- and long-term results; $7.1 \%$ cumulative need for TLR, $6.1 \%$ cardiac mortality rate, and $17.3 \%$ MACE rate at 2 years. Data from randomized trials should help to select the stent-of-choice for use in ULMCA and the strategy for use in true bifurcations.

\section{ACKNOWLEDGEMENTS}

We thank the rest of the team (physicians, nurses and auxiliary staff) of the Hemodynamic Unit of the Complejo Hospitalario de Jaén without whose enthusiastic support this study would not have been possible.

\section{REFERENCES}

[1] Eagle, K.A., Guyton, R.A., Davidoff, R., Edwards, F.H., Ewy, G.A., Gardner, T.J., Hart, J.C., Herrmann, H.C., Hillis, L.D., Hutter Jr., A.M., Lytle, B.W., Marlow, R.A, Nugent, W.C., Orszulak, T.A., Antman, E.M., Smith Jr., S.C., Alpert, J.S., Anderson, J.L., Faxon, D.P., Fuster, V., Gibbons, R.J., Gregoratos, G., Halperin, J.L., Hiratzka, L.F. and Hunt, S.A. (2004) ACC/AHA 2004 guideline update for coronary artery bypass graft surgery: Summary article: A report of the American college of cardiology/American heart association task force on practice guidelines (committee to update the 1999 guidelines for coronary artery bypass graft surgery). Circulation, 110, 1168-1176. doi:10.1161/01.CIR.0000138790.14877.7D

[2] Morice, M.C., Serruys, P.W., Kappetein, A.P., Feldman, T.E., Stahle, E., Colombo, A., Mack, M.J., Holmes, D.R., Torracca, L., van Es, G.A., Leadley, K., Dawkins, K.D. and Mohr, F. (2010) Outcomes in patients with de novo left main disease treated with either percutaneous coronary intervention using paclitaxel-eluting stents or coronary artery bypass graft treatment in the synergy between percutaneous coronary intervention with TAXUS and cardiac surgery (SYNTAX) trial. Circulation, 121, $2645-$ 2653. doi:10.1161/CIRCULATIONAHA.109.899211

[3] Kim, U., Park, J.S., Seol, S.H., Yang, T.H., Kim, S.M., Kim, D.K., Kim, D.I., Kim, D.S., Lee, W.J., Lee, S.H., Hong, G.R., Shin, D.G., Kim, Y.J., Shim, B.S., Cho, Y.K., Kim, H.S., Nam, C.W., Hur, S.H., Kim, K.B. and Kim, Y.N. (2009) Two-year outcomes of the sirolimus-eluting stent according to unprotected left main lesion. Clinical Cardiology, 32, 332-336. doi:10.1002/clc.20563

[4] Mehilli, J., Kastrati, A., Byrne, R.A., Bruskina, O., Iijima, R., Schulz, S., Pache, J., Seyfarth, M., Massberg, S., Laugwitz, K.L., Dirschinger, J. and Schomig, A. (2009) Paclitaxel-versus sirolimus-eluting stents for unprotected left main coronary artery disease. Journal of the American College of Cardiology, 53, 1760-1768.

doi:10.1016/i.jacc.2009.01.035

[5] Meliga, E., Garcia-Garcia, H.M., Valgimigli, M., Chieffo, A., Biondi-Zoccai, G., Maree, A.O., Gonzalo, N., Cook, S., Marra, S., Moretti, C., De, S.S., Palacios, I.F., Windecker, S., van, D.R., Colombo, A., Sheiban, I. and Serruys, P.W. (2009) Impact of drug-eluting stent selection on long-term clinical outcomes in patients treated for unprotected left main coronary artery disease: The sirolimus vs paclitaxel drug-eluting stent for left main registry (SPDELFT). International Journal of Cardiology, 137, 16-21. doi:10.1016/j.ijcard.2008.06.006

[6] Palmerini, T., Sangiorgi, D., Marzocchi, A., Tamburino, C., Sheiban, I., Margheri, M., Vecchi, G., Sangiorgi, G., Ruffini, M., Bartorelli, A.L., Briguori, C., Vignali, L., di, P.F., Ramondo, A., Inglese, L., de, C.M., Bolognese, L., Benassi, A., Palmieri, C., Filippone, V., Barlocco, F., Lauria, G. and De Servi, S. (2009) Ostial and midshaft lesions vs. bifurcation lesions in 1111 patients with unprotected left main coronary artery stenosis treated with drug-eluting stents: results of the survey from the Italian society of invasive cardiology. European Heart Journal, 30, 2087-2094. doi:10.1093/eurheartj/ehp223

[7] Khattab, A.A., Hamm, C.W., Senges, J., Toelg, R., Geist, V., Bonzel, T., Kelm, M., Levenson, B., Neumann, F.J., Nienaber, C.A., Pfannebecker, T., Sabin, G., Schneider, S., Tebbe, U. and Richardt, G. (2007) Sirolimus-eluting stent treatment for unprotected versus protected left main coronary artery disease in widespread clinical routine: 6-month and 3-year clinical follow-up results from the prospective multicentre German cypher registry. Heart, 93, 1251-1255. doi:10.1136/hrt.2007.104703

[8] Kedhi, E., Joesoef, K.S., McFadden, E., Wassing, J., van Mieghem, C., Goedhart, D. and Smits, P.C. (2010) Second-generation everolimus-eluting and paclitaxel-eluting 
stents in real-life practice (COMPARE): A randomised trial. Lancet, 375, 201-209.

doi:10.1016/S0140-6736(09)62127-9

[9] Serruys, P.W., Ruygrok, P., Neuzner, J., Piek, J.J., Seth, A., Schofer, J.J., Richardt, G., Wiemer, M., Carrie, D., Thuesen, L., Boone, E., Miquel-Herbert, K. and Daemen, J. (2006) A randomised comparison of an everolimuseluting coronary stent with a paclitaxel-eluting coronary stent: The SPIRIT II trial. Euro-Intervention, 2, 286-294.

[10] Stone, G.W., Midei, M., Newman, W., Sanz, M., Hermiller, J.B., Williams, J., Farhat, N., Mahaffey, K.W., Cutlip, D.E., Fitzgerald, P.J., Sood, P., Su, X. and Lansky, A.J. (2008) Comparison of an everolimus-eluting stent and a paclitaxel-eluting stent in patients with coronary artery disease: A randomized trial. The Journal of the American Medical Association, 299, 1903-1913. doi:10.1001/jama.299.16.1903

[11] Stone, G.W., Rizvi, A., Newman, W., Mastali, K., Wang, J.C., Caputo, R., Doostzadeh, J., Cao, S., Simonton, C.A., Sudhir, K., Lansky, A.J., Cutlip, D.E. and Kereiakes, D.J. (2010) Everolimus-eluting versus paclitaxel-eluting stents in coronary artery disease. The New England Journal of Medicine, 362, 1663-1674.

doi:10.1056/NEJMoa0910496

[12] De Waha, A., Dibra, A., Byrne, R.A., Ndrepepa, G., Mehilli, J., Fusaro, M., Laugwitz, K.-L., Massberg, S., Schömig, A. and Kastrati, A. (2011) Everolimus-eluting versus sirolimus-eluting stents a meta-analysis of randomized trials. Circulation: Cardiovascular Interventions, 4, 371-377.

doi:10.1161/CIRCINTERVENTIONS.111.963256

[13] Onuma, Y., Kukreja, N., Piazza, N., Eindhoven, J., Girasis, C., Schenkeveld, L., van Domburg, R. and Serruys, P.W. (On Behalf of the Interventional Cardiologists of the Thoraxcenter (2000 to 2007)) (2009) The everolimuseluting stent in real-world patients 6-month follow-up of the X-SEARCH (Xience V) stent evaluated at Rotterdam Cardiac Hospital registry. Journal of the American College of Cardiology, 54, 269-276.

[14] Cutlip, D.E., Windecker, S., Mehran, R., Boam, A., Cohen, D.J., van Es, G.A., Steg, P.G., Morel, M.A., Mauri, L., Vranckx, P., McFadden, E., Lansky, A., Hamon, M., Krucoff, M.W. and Serruys, P.W. (On Behalf of the Academic Research Consortium) (2007) Clinical end points in coronary stent trials: A case for standardized definitions. Circulation, 115, 2344-2351. doi:10.1161/CIRCULATIONAHA.106.685313

[15] Sianos, G., Morel, M.A., Kappetein, A.P., Morice, M.C., Colombo, A., Dawkins, K., van den Brand, M., Van Dyck, N., Russell, M.E., Mohr, F.W. and Serruys, P.W. (2005) The SYNTAX score: An angiographic tool grading the complexity of coronary artery disease. EuroIntervention, 1, 219-227.

[16] Park, S.J., Kim, Y.H., Park, D.W., Lee, S.W., Kim, W.J., Suh, J., Yun, S.C., Lee, C.W., Hong, M.K., Lee, J.H. and Park, S.W. (MAIN-COMPARE Investigators) (2009) Impact of intravascular ultrasound guidance on long-term mortality in stenting for unprotected left main coronary artery stenosis. Circulation: Cardiovascular Interventions, 2, 167-177.

\section{doi:10.1161/CIRCINTERVENTIONS.108.799494}

[17] Vaquerizo, B., Lefèvre, T., Darremont, O., Silvestri, M., Louvard, Y., Leymarie, J.L., Garot, P., Routledge, H., de Marco, F., Unterseeh, T., Zwahlen, M. and Morice, M.C. (2009) Unprotected left main stenting in the real world: Two-year outcomes of the French left main taxus registry. Circulation, 119, 2349-2356. doi:10.1161/CIRCULATIONAHA.108.804930

[18] Meliga, E., Garcia-Garcia, H.M., Valgimigli, M., Chieffo, A., Biondi-Zoccai, G., Maree, A.O., Cook, S., Reardon, L., Moretti, C., De Servi, S., Palacios, I.F., Windecker, S., Colombo, A., van Domburg, R., Sheiban, I., Serruys, P.W. (2008) Longest available clinical outcomes after drugeluting stent implantation for unprotected left main coronary artery disease: The DELFT (drug eluting stent for LeFT main) registry. Journal of the American College of Cardiology, 51, 2212-2219. doi:10.1016/j.jacc.2008.03.020

[19] Wood, F.O., Saylors, E.K., Schneider, J.E., Jobe, R.L. and Mann, J.T. 3rd. (2008) Unprotected left main disease managed with drug-eluting stents: Long-term outcome of 100 patients with increased surgical risk. Catheterization and Cardiovascular Interventions, 71, 533-538. doi:10.1002/ccd.21447

[20] Toyofuku, M., Kimura, T., Morimoto, T., Hayashi, Y., Ueda, H., Kawai, K., Nozaki, Y., Hiramatsu, S., Miura, A., Yokoi, Y., Toyoshima, S., Nakashima, H., Haze, K., Tanaka, M., Take, S., Saito, S., Isshiki, T. and Mitsudo, $\mathrm{K}$. (On Behalf of the j-Cypher Registry Investigators) (2009) Three-year outcomes after sirolimus-eluting stent implantation for unprotected left main coronary artery disease. Insights from the j-Cypher Registry Circulation, 120, 1866-1874.

[21] Wu, X.-F., Chen, Y.-D., Kubo, T., Ge, C.-J., Ren, F., Wu, X., Chen, W.-J., Zhou, Y., Liu, H. and Lv, S. (2010) Long-term (4-year) outcomes and predictors of adverse cardiac events after sirolimus-eluting stent implantation in unprotected left main coronary artery. International Heart Journal, 51, 377-382. doi:10.1536/ihj.51.377

[22] Lee, J.-Y., Park, D.-W., Yun, S.-C., Lee, S.-W., Kim, Y.-K., Lee, C.W., Hong, M.-K., Park, S.-W. and Park, S.-J. (2009) Long-term clinical outcomes of sirolimusversus paclitaxel-eluting stents for patients with unprotected left main coronary artery disease. Analysis of the MAIN-COMPARE (Revascularization for unprotected left main coronary artery stenosis: Comparison of percutaneous coronary angioplasty versus surgical revascularization) registry. Journal of the American College of Cardiology, 54, 853-859. doi:10.1016/j.jacc.2009.04.071

[23] Latib, A., Ferri, L., Ielasi, A., Godino, C., Chieffo, A., Magni, V., Bassanelli, G., Sharp, A.S.P., Gerber, R., Michev, I., Carlino, M., Airoldi, F., Sangiorgi, G.M., Montorfano, M. and Colombo, A. (2009) Clinical outcomes after unrestricted implantation of everolimus-eluting stents. Journal of the American College of Cardiology, 2, 1219. 1226.

[24] Stone, G.W., Midei, M., Newman, W., Sanz, M., Hermiller, J.B., Williams, J., Farhat, N., Caputo, R., Xenopoulos, N., Applegate, R., Gordon, P., White, R.M., Sudhir, K., Cutlip, D.E. and Petersen, J.L. (SPIRIT III Inves- 
tigators) (2009) Randomized comparison of everolimuseluting and paclitaxel-eluting stents. Two-year clinical follow-up from the clinical evaluation of the Xience $\mathrm{V}$ everolimus-eluting coronary stent system in the treatment of patients with de novo native coronary artery lesions (SPIRIT) III trial. Circulation, 119, 680-686. doi:10.1161/CIRCULATIONAHA.108.803528
[25] Joner, M., Nakazawa, G., Finn, A.V., Quee, S.C., Coleman, L., Acampado, E., Wilson, P.S., Skorija, K., Cheng, Q., Xu, X., Gold, H.K., Kolodgie, F.D. and Virmani, R. (2008) Endothelial cell recovery between comparator polymer-based drug-eluting stents. Journal of the American College of Cardiology, 52, 333-342. doi:10.1016/j.jacc.2008.04.030 